\title{
Telemedicina, un nuevo frente en la pandemia por COVID-19
}

\author{
Telemedicine, a new front in the COVID-19 pandemic
}

\author{
Gilberto F. Vázquez-de Anda* \\ Facultad de Medicina, Universidad Autónoma del Estado de México, Estado de México, México
}

Nunca en la historia de la medicina se había contado con un recurso que revolucionaría la atención médica de la forma en que la telemedicina lo ha hecho en año y medio de pandemia de COVID-19. En ella convergen tecnología simplificada de telecomunicaciones que incluye audio y video en tiempo real, el internet de banda ancha, las plataformas de teleconferencia de acceso domiciliario, los teléfonos con cámara fotográfica con la posibilidad de proporcionar fotografías de pantalla, el almacenamiento de documentos, material fotográfico, video y audio; las redes de comunicación social y las plataformas comerciales de expediente electrónico al alcance de los médicos.

Todo ello permitió que desde el inicio de la pandemia, el sector salud y la población comprendieran la importancia de hacer uso de la telemedicina y enfrentar la pandemia de COVID-19. Al principio de la pandemia, el uso de la telemedicina se dio de forma instintiva, práctica y, podría decirse, hasta natural. Visto en la línea del tiempo y en el contexto histórico de la práctica médica, la telemedicina finalmente alcanzó su nivel de paradigma de la atención médica del siglo XXI. La clave del éxito radicó no en la conciencia colectiva del progreso de la medicina o la tecnología, sino en el distanciamiento social, el confinamiento y la diminución de la movilidad recomendados por la salud pública ante la virulencia y letalidad de un virus, el SARS-CoV-2.

La telemedicina no es un término nuevo, se fue desarrollando a finales del siglo XIX y a lo largo del siglo XX. La aparición del telégrafo y el teléfono a principios del siglo $\mathrm{XX}$ permitió la trasmisión de datos clínicos entre dos médicos o comunidades distantes uno del otro, propiciada, por un lado, por la falta de médicos y, por el otro, la distancia geográfica y la falta de vías de comunicación.

En el primer tercio del siglo anterior se dispuso, además, de las ondas de radio y, posteriormente, de las señales de televisión. Un punto angular para el desarrollo de la telemedicina lo constituyó la carrera espacial, ya con el uso de las señales satelitales se consolidó la telemetría, la cual fue ampliamente utilizada en países del hemisferio norte en los sistemas de atención prehospitalaria.

La escasez de personal médico en zonas distantes ha sido la motivación principal para el desarrollo de programas de telemedicina como la conocemos hoy en día. La aparición de la computadora permitió la digitalización de imágenes y la aparición del internet hizo posible la trasmisión de documentos digitalizados. El avance vertiginoso de las telecomunicaciones y la aparición de los teléfonos celulares con audio y video, así como la aparición de las redes sociales y la robótica aplicada a la medicina, han posibilitado la trasmisión de datos clínicos en tiempo real y la comunicación entre equipos médicos distantes unos de otros, lo que ha dado lugar a los términos telesalud, telemedicina y telepresencia robótica en salud.

La prioridad de dar atención médica de acuerdo con las necesidades de cada paciente ha promovido ampliamente el uso de la telemedicina, con la cual se ha logrado más rápido acceso de los pacientes al sistema de salud, por lo que ha sido considerada por algunos como la primera opción de orientación y consulta médica. La experiencia en México con el uso de
Correspondencia:

*Gilberto F. Vázquez-de Anda

E-mail: gf_vazquez@hotmail.com

0016-3813/С 2021 Academia Nacional de Medicina de México, A.C. Publicado por Permanyer. Este es un artículo open access bajo la licencia CC BY-NC-ND (http://creativecommons.org/licenses/by-nc-nd/4.0/).

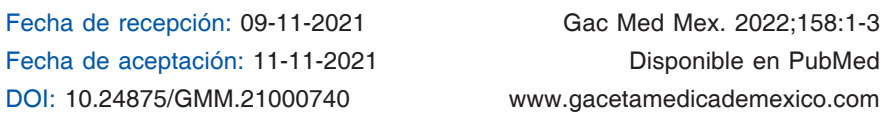


telemedicina en la pandemia de influenza AH1N1 fue con un programa de telepresencia robótica, con el cual se observó el beneficio de disponer de asistencia experimentada en cuidados críticos a distancia en el Estado de México.

A mediados de diciembre de 2019 se documentaron casos de una nueva enfermedad respiratoria en Wuhan, provincia de China, la cual se declaró en alerta sanitaria el 31 de diciembre; para el 11 de marzo de 2020 se declaró la pandemia. El causante de la pandemia es el virus SARS-CoV-2, cuyo cuadro clínico predominante es de infección en el aparato respiratorio, que en sus formas graves desarrolla neumonía, a la cual se le denominó COVID-19. La rapidez del contagio y el número creciente de pacientes infectados fue motivo de preocupación mundial respecto a la capacidad hospitalaria (camas de cuidados intensivos y ventiladores mecánicos) y de recursos humanos (médicos y enfermeras intensivistas y personal de inhaloterapia) de los sistemas de salud, por lo que se dio paso a la planeación de convertir áreas de hospitalización en áreas de atención especial para pacientes con COVID-19. Se adquirió equipo de monitoreo y atención respiratoria, así como para protección del personal de salud; se entrenó al personal no experto en cuidados intensivos y se estableció un tratamiento base para los pacientes en los diferentes estadios de la enfermedad.

La aparición de SARS-CoV-2 y su rápida expansión en el mundo con sus letales consecuencias constituyó el factor primordial para implementar o incrementar el número de servicios de telemedicina en los sistemas de salud y acercar la atención médica a pacientes con sospecha de COVID-19, manteniendo el distanciamiento social y evitando la propagación de la enfermedad.

En México, el número de pacientes se incrementó rápidamente, por lo que se observó un intercambio cotidiano de datos clínicos de pacientes con COVID19 , ya fuera a través de teléfonos celulares o internet. El uso de plataformas de videoconferencias dio por hecho la practicidad y efectividad de la telemedicina para proporcionar orientación y atención médica a distancia. Se desconoce el número de consultas otorgadas mediante telemedicina, pero se puede asegurar que la mayoría de los médicos ha llegado a practicarla en algún momento durante la pandemia de COVID-19.
La teleconsulta se dio continua y cotidianamente en sus diferentes formas a lo largo de la pandemia, ya fuera con el intercambio de datos clínicos y de laboratorio mediante imagen de manera asincrónica, o de pacientes a personal de salud o entre dos equipos de salud de manera sincrónica. En esta pandemia se observó claramente los beneficios de la telemedicina: elimina la distancia y las circunstancias geográficas y hace posible la ubicuidad, estar presente en más de dos sitios al mismo tiempo.

Entre los servicios que se implementaron con telemedicina se encuentran el triaje domiciliario, seguimiento de contactos en cuarentena, consulta y seguimiento domiciliario, transferencia de pacientes que desarrollaron hipoxemia y "hospitalización en casa", en los casos en los que se enfrentó saturación de camas de hospitalización o en los que se decidió por voluntad propia no asistir al hospital. También se otorgó asistencia y orientación a equipos hospitalarios sin experiencia en la atención de pacientes críticos con COVID-19 para la toma de decisiones.

Entre los beneficios observados con esta práctica médica a distancia se encuentra la expansión del número operativo de médicos, expansión del número de camas destinadas a la atención de pacientes con COVID-19, optimización de recursos hospitalarios al tener un servicio de triaje domiciliario, referencia oportuna de pacientes a un hospital o centro COVID cuando presentaron deterioro respiratorio, cuidado domiciliario de contactos y pacientes con enfermedad leve, disminución del contagio por portadores de SARS-CoV-2, disminución del riesgo de contagio por parte del personal de salud, atención domiciliaria y seguimiento de pacientes con enfermedades crónicas que se encuentran en distanciamiento social y disminución de los costos de atención.

Entre las limitaciones de la telemedicina se identifica la dependencia de la tecnología, como tener adecuada señal de internet, dispositivos de teleconferencia adecuados (teléfonos celulares de los llamados de alta gama, computadoras con audio y video) y acceso a plataformas de teleconferencia y a los sistemas de PAC para la interpretación de imágenes y laboratorio clínico, así como a plataformas de expediente electrónico para resguardo de la información personal. También se encuentran las limitaciones de la propedéutica clínica propia de la práctica de telemedicina: incapacidad para apreciar las alteraciones del color de la piel y para realizar exploración física en general, 
palpación y auscultación. La mayor parte de la consulta y tomas de decisiones se basan en el interrogatorio y la observación del paciente, así como en el uso de recursos subrogados domiciliarios como el oxímetro de pulso, termómetro digital o baumanómetro electrónico.

En la actual pandemia de COVID-19 se dio por sentado el beneficio potencial de la telemedicina, ya que los recursos tecnológicos en telecomunicación son suficientes para otorgar orientación y atención médica de bajo costo sin limitación física o geográfica, lo que demarca un nuevo paradigma en la atención médica en el que se evoluciona de la medicina presencial a la medicina virtual. Con base en lo anterior, se puede decir que la telemedicina constituyó un frente de atención de COVID-19 intangible, pero efectivo al potencializar el número de médicos y personal de salud a lo largo del territorio nacional. Nuevas formas de exploración física subrogada y una nueva propedéutica clínica virtual aún deberán ser desarrolladas. 